\title{
Human Periodontal Fibroblast Response to Enamel Matrix Derivative, Amelogenin, and Platelet-Derived Growth Factor-BB
}

\author{
Chol H. Chong, * David L. Carnes, ${ }^{\dagger}$ Alan J. Moritz, ${ }^{\ddagger}$ Thomas Oates, ${ }^{\dagger}$ Ok Hee Ryu,,
} James Simmer, $\|$ and David L. Cochran ${ }^{\dagger}$

Background: The ideal goal of clinical therapy in periodontal defects is regeneration of all lost structures. For regeneration to occur, cell proliferation, migration, and extracellular matrix synthesis are prerequisites. Attempts at regeneration of periodontal defects by guided tissue regeneration using bone grafts and membranes have not always yielded predictable results. Recently, attempts at engineering the defects using various materials have shown promising results. Two such approaches have been used to regenerate periodontal defects, one using extracellular matrix such as enamel matrix proteins and the other using growth factors. However, to our knowledge, no study has looked at combining these two approaches to achieve potentially even greater regeneration.

Methods: Primary human periodontal ligament (PDL) fibroblasts were explanted, and alkaline phosphatase (ALK PHOS) activity was determined. Phenotypically different cell lines were incubated for 1, 3, 6, and 10 days in $0.2 \%$ fetal bovine serum (FBS) media containing different concentrations of either enamel matrix derivative (EMD), amelogenin, platelet-derived growth factor-BB (PDGF-BB), EMD + PDGF-BB, or amelogenin + PDGFBB. A culture of $0.2 \%$ FBS alone served as a negative control, and a culture of $10 \%$ FBS served as a positive control. Cell proliferation was measured using a Coulter counter to determine the cell number. The effects on a wound-fill model were evaluated by scraping a 3-mm wide cell-free zone in PDL monolayers across the diameter of the tissue-culture plate and determining PDL cell migration into the cell-free zone using computer assisted histomorphometry.

Results: Compared to the control, only EMD + PDGF-BB significantly increased PDL cell proliferation in an ALK PHOS $(-)$ cell line $(P<0.001)$, and EMD alone, EMD + PDGF-BB, and amelogenin + PDGF-BB significantly increased PDL cell proliferation in an ALK PHOS $(+)$ cell line $(P<0.001)$ with EMD + PDGF-BB showing a trend for greater proliferation than either PDGF or EMD alone. Individually, EMD and amelogenin had no significant effect on PDL cell proliferation. In the wound-fill experiment, all factors and their combinations except amelogenin significantly enhanced cell migration compared to the control $(P<0.05)$ at the wound edge. In addition, EMD + PDGF-BB had additive effects on the ALK PHOS (-) cell line at the wound edge. At the center of the wound, neither EMD nor amelogenin had a significant wound-fill effect. However, the combination of EMD + PDGF-BB additively increased wound fill for both ALK PHOS (+) and ALK PHOS (-) cells.

Conclusions: The combination of EMD and PDGF-BB produces greater proliferative and wound-fill effects on PDL cells than each by themselves. If these combined effects can be translated clinically, one may see greater regeneration in periodontal defects with this combination. However, amelogenin does not have significant effects on PDL cell proliferation or migration by itself. This may suggest that either another enamel matrix component in EMD may be responsible for some of its clinical effects, or that amelogenin alone may not trigger the regenerative potential of periodontal tissues and that it requires a combined interaction with other enamel matrix components of EMD to direct the regenerative process. J Periodontol 2006;77:1242-1252.

\section{KEY WORDS}

Amelogenin; EMDOGAIN; PDGF-BB.

\footnotetext{
* Department of Periodontics, Wilford Hall Medical Center, Lackland Air Force Base, TX

$\dagger$ Department of Periodontics, University of Texas Health Science Center, San Antonio, TX

\# Department of Periodontics, Spangdahlem Air Base, Germany.

$\S$ National Institute of Dental and Craniofacial Research, National Institutes of Health, Human Craniofacial Genetics Section, Bethesda, MD.

I| Department of Pediatrics, School of Dentistry, University of Michigan, Ann Arbor, MI.
} 
$\mathrm{E}$ namel matrix derivative (EMD) is a freeze-dried enamel matrix protein extract or gel derived from developing tooth buds of 6-month-old piglets. Its treatment rationale is based on the observation that initiation of acellular cementum is regulated by the inner enamel epithelium of Hertwig's epithelial root sheath (HERS). ${ }^{1}$ Also, the proteins found in acellular cementum have been shown to resemble enamel matrix proteins. ${ }^{2}$ Histologically, EMD applied to root surfaces has been shown to produce regeneration through the formation of bone, periodontal ligament (PDL), and acellular cementum. ${ }^{3}$ Others have observed regeneration with cementum that was mostly cellular rather than acellular, ${ }^{4}$ and regeneration was not always consistent. ${ }^{5}$

Clinically, EMD has shown very promising results. In early human trials, EMD demonstrated an ability to enhance regeneration when applied in conjunction with periodontal surgery. ${ }^{6}$ The clinical effects of EMD were compared to other treatment modalities and showed similar, if not better, clinical results. Hejil et al. ${ }^{7}$ compared the effects of EMD versus modified Widman flap (MWF) in mostly 1 - and 2 -wall defects and found that EMD-treated sites had $2.6 \mathrm{~mm}$ radiographic bone gain, whereas the MWF sites did not show improvement from baseline. Froum et al. ${ }^{8}$ also compared the effects of EMD in periodontal defects compared to MWF alone and showed superior defect fill with EMD at reentry. In horizontal defects, EMD in conjunction with open-flap debridement maintained the attachment level, whereas debridement alone showed a significant loss of attachment. ${ }^{9}$ Compared to guided tissue regeneration (GTR), EMD generally showed comparable results in attachment gain in intrabony defects. ${ }^{10,11}$ In addition to intrabony defects, EMD used in conjunction with coronally advanced flaps in recession defects resulted in root coverage similar to coronally advanced flap with subepithelial connective tissue, and one histologic specimen even showed regeneration of cementum, bone, and PDL. ${ }^{12,13}$ When the long-term clinical results of EMD were assessed, Sculean et al. ${ }^{14}$ found that the clinical improvements obtained with EMD can be maintained over a 4-year period.

Clinical reports continue to support EMD as a regenerative material in periodontal defects, but the mechanism of regeneration achieved by EMD is largely unknown. ${ }^{15}$ EMD has been shown to selectively enhance the proliferation of PDL cells, but not of epithelial cells. ${ }^{16}$ Kawase et al. ${ }^{17}$ have also shown EMD's effect as a cytostatic agent against epithelial cells, thus suppressing the downgrowth of junctional epithelium onto root surfaces. EMD's effect on bone formation suggests osteopromotive rather than osteoinductive potential. Boyan et al. ${ }^{18}$ placed demin- eralized freeze-dried bone allograft (DFDBA) in combination with EMD in mouse calf muscle and found enhanced bone induction compared to DFDBA alone. In vitro experiments ${ }^{19}$ using osteosarcoma cells showed that EMD can stimulate proliferation and differentiation of osteoblasts depending on their state of maturation. EMD has also been suggested to upregulate intracellular cyclic adenosine monophosphate (cAMP) levels and to enhance secretion of transforming growth factor-beta (TGF- $\beta$ ) and interleukin-6 (IL-6). ${ }^{19-21}$ van der Pauw et al. ${ }^{21}$ observed that EMD increased alkaline phosphatase (ALK PHOS) and subsequent stimulation of PDL attachment but not proliferation.

The idea that EMD mimics the primary formation of roots and their supporting structures is currently under debate. The majority of EMD is $90 \%$ amelogenin, and the remaining $10 \%$ is primarily proline-rich nonamelogenins, tuftelin, tuft protein, enamelin, and serum proteins. Enamel proteins are not shown to be present in the region of acellular cementum growth during root development but only in the apical portion of the root. ${ }^{22}$ Recently, amelogenin has been found to be absent along the developing root surfaces of mouse molars. ${ }^{23}$ Although EMD clearly shows potential for stimulating regeneration, as mentioned above, the mechanism of action of EMD is not well understood, and its interaction with other growth factors and proteins in the periodontal wound site needs to be studied further.

Amelogenin is an enamel matrix protein $\sim 25 \mathrm{kDa}$ produced by epithelial-derived ameloblasts. This protein is rapidly degraded to a more stable form $\sim 20$ $\mathrm{kDa}$. Structurally, recombinant amelogenin forms spheres of about 100 molecules, measuring $20 \mathrm{~nm}$ in diameter. This corresponds to the spacing between developing enamel crystallites, suggesting the role of amelogenin in the structural framework of enamel during development. ${ }^{24,25}$ Recently, leucine-rich amelogenin peptides have been shown to have a direct effect on cementoblast activity. ${ }^{26}$ As the major component of $\mathrm{EMD}$, amelogenin may contribute significantly to the observed biologic effects of EMD.

Platelet-derived growth factor (PDGF) is a dimeric molecule of $A$ and $B$ and recently discovered $C$ and $D$ chains. It is secreted primarily by the $\alpha$-granules of platelets, but activated macrophages and fibroblasts produce it as well. PDGF, in concert with other growth factors, is an important mediator of wound healing. PDGF stimulates cells by binding to $\alpha$ - and $\beta$-receptors found on cell surfaces. The $\alpha$-receptors can bind both $A$ and $B$ chains, but the $\beta$-receptors can only bind to $B$ chains. Lynch ${ }^{27}$ first discovered that PDGF can promote regeneration of bone, cementum, and periodontal ligament. Studies have shown that PDGF-BB is more effective in mitogenesis and chemotaxis 
compared to either $\mathrm{AA}$ or $\mathrm{AB} .^{28}$ The addition of PDGF-BB has been shown to improve both migration and proliferation of cells in the periodontium. ${ }^{29-35}$ In cultures of quiescent PDL cells, PDGF-BB stimulates the PDL-fibroblast cells to divide without the addition of other factors. ${ }^{36}$ Mumford et al., ${ }^{37}$ using an in vitro wound model to investigate PDL and gingival fibroblasts, found that wound fill by PDL cells significantly increased with the addition of PDGF-BB. The combination of PDGF-BB and insulin-like growth factor has been shown to have synergistic effects on the regeneration of defects in animals. ${ }^{38-40}$ Matsuda et al. ${ }^{31}$ have shown that recombinant human PDGF (rhPDGF) can stimulate collagen synthesis by PDL cells. Interestingly, cultured human PDL cells exposed to EMD showed increased production of PDGF-AB. ${ }^{20}$ More recently, Papadopoulos et al. ${ }^{41}$ have shown that PDGF-BB in combination with bone allografts synergistically stimulated PDL proliferation in vitro, and Nevins et al. ${ }^{42}$ and Camelo et al. ${ }^{43}$ have shown histologic regeneration in Class II furcation defects by using rhPDGF-BB and bone allograft in humans. These findings support an important role of PDGF-BB in the regeneration of the periodontal wound.

Two different types of molecules have been studied individually for tissue regeneration; one type are extracellular matrix proteins and the other type are growth factors. In natural wound healing, both of these types of molecules are important. Thus, it is plausible to combine EMD and PDGF-BB in a wound model to attempt an even greater regenerative potential than each has by itself. Therefore, the objective of the present investigation was to evaluate the effects of EMD, PDGF-BB, and amelogenin individually and in combinations on the proliferation and wound-fill effects of human PDL fibroblasts.

\section{MATERIALS AND METHODS}

\section{Tissue Sample Collection}

All tissue samples were obtained from healthy patients ranging in age from 25 to 55 years and without periodontal disease following guidelines established by the Institutional Review Board of the University of Texas Health Science Center at San Antonio. All tissue samples were handled using an aseptic technique and directly placed in 50-ml tissue culture tubes containing Dulbecco's modified Eagle's medium (DMEM) containing $1 \%$ penicillin/streptomycin, $1 \%$ fungizone, and $10 \%$ fetal calf serum. Remaining procedures were conducted in a sterile environment under a laminarflow hood.

Primary human PDL cell lines were cultivated from thin layers of PDL tissues attached to the middle onethird of extracted premolar and molar tooth roots. Using sharp sterile blades, PDL tissue fragments were removed from each tooth and placed in 60-ml tissue- culture plastic plates containing $4 \mathrm{ml}$ DMEM containing 4,500 mg/L D-glucose, $1 \%$ penicillin/streptomycin, $1 \%$ fungizone, and $10 \%$ fetal calf serum. A small piece of stainless steel wire grid was placed on top of the fragments to prevent movement of explants and to promote the outgrowth of new cells. Within 3 weeks, $\sim 40 \%$ PDL explants were successfully forming primary cultures with a sufficient number of new cells. The wire grid was removed from the plate to permit more new cell growth. PDL cells were maintained at $37^{\circ} \mathrm{C}$ in humidified air containing $5 \% \mathrm{CO}_{2}$ and $95 \%$ air. Upon reaching confluence, cells were removed by incubation with $0.25 \%$ trypsin and passaged to $100-\mathrm{ml}$ tissue culture plates. Four cell lines from four different individuals were used at passages four to nine.

\section{Alkaline Phosphatase Assay}

Alkaline phosphatase activity for individual cell lines was determined using cell monolayers. A T-75 flask of PDL cells was trypsinized and resuspended in culture medium at a cell density of 18,800 cells $/ \mathrm{ml}$. One milliliter of the cell suspension was placed into each of the 12 wells $\left(10,000\right.$ cells $\left./ \mathrm{cm}^{2}\right)$ on two 24 -well culture plates. The cells were cultured to confluence at $37^{\circ} \mathrm{C}$ in a $5 \% \mathrm{CO}_{2}: 95 \%$ air. One plate was subjected to histochemical staining using an alkaline phosphatase conjugate substrate kit ${ }^{\text {Il }}$ following the manufacturer's instructions. The resultant staining was photographed at $\times 100$ magnification. The media was removed from the wells on the second plate, and the cells were washed twice with phosphate buffered saline. After addition of $0.01 \%$ Triton X-100 lysis buffer, the plates were sealed with parafilm and placed at $-80^{\circ} \mathrm{C}$. The cells were thawed and refrozen three times to break open the cells. The liquid and cells were transferred to labeled microfuge tubes and stored frozen until the assay was performed. Cells were centrifuged prior to the assay to remove debris. The supernatant was used for the assay. The assay solutions were as follows: 1) $1.5 \mathrm{M}(6.68 \mathrm{~g} / 50 \mathrm{ml})$ 2-amino-2-methyl-1-propanol (2A2MIP), pH 10.25 (titrated with $\mathrm{HCl}$ ); 2) $20 \mathrm{mM}$ pnpp (5.26 mg/ml); and 3) $10 \mathrm{mM} \mathrm{MgCl} 2$. The working reagent contained one part solution 1 plus one part solution 2 plus one part solution 3 . The stop solution was $1 \mathrm{~N} \mathrm{NaOH}$. Standards were prepared in the same buffer as the samples. Using 96 -well plates, $50 \mu \mathrm{l}$ of each standard solution in duplicate was pipetted into wells of the first two columns, $50 \mu \mathrm{l}$ of buffer in duplicate served as the blank, and $50 \mu \mathrm{l}$ of each sample was pipetted in duplicate in the remaining wells. A total of $50 \mu \mathrm{l}$ prepared working reagent was added to each well and incubated at $37^{\circ} \mathrm{C}$ for 1 hour. The reaction was stopped with the addition of $100 \mu \mathrm{l} /$ well of $1 \mathrm{~N} \mathrm{NaOH}$. The

Il Catalog number 170-6432, Bio-Rad, Hercules, CA. 
optical density of each well was determined using a plate reader ${ }^{\#}$ at $405 \mathrm{~nm}$.

Protein was determined on the same samples using the bicinchoninic acid (BCA) procedure. * Standards were prepared using the stock solution of $1 \mathrm{mg} / \mathrm{ml}$ of bovine serum albumin (BSA) supplied with the kit. The working reagent consisted of 50 parts reagent A and one part reagent B. A total of $10 \mu \mathrm{l} \mathrm{buffer} \mathrm{blank,}$ and $10 \mu \mathrm{l}$ of each standard and sample were pipetted in duplicate into the wells of a 96-well plate. A total of $200 \mu \mathrm{l} \mathrm{BCA}$ working reagent was added to each well, and the plates were incubated at $37^{\circ} \mathrm{C}$ for 30 minutes. The optical density of each well was determined using a plate reader ${ }^{\dagger \dagger}$ at $562 \mathrm{~nm}$. Alkaline phosphatasespecific activity was calculated for each sample and expressed as $\mathrm{nmol} / \mu \mathrm{g}$ protein. The data were expressed as the mean \pm SEM $(\mathrm{N}=12)$ for each PDL cell type.

\section{Cell Proliferation Assay}

Tissue-culture plates (24-well) were seeded with PDL cells using $1 \times 10^{4}$ cells per well in $1 \mathrm{ml}$ DMEM containing $10 \%$ fetal bovine serum (FBS). The culture plates were incubated at $37^{\circ} \mathrm{C}$ in humidified air with $5 \% \mathrm{CO}_{2}$ for 6 hours. The media was removed and replaced with DMEM alone for 24 hours, allowing the cells to become quiescent. DMEM was removed, and the desired concentrations of EMD, $^{\ddagger}$ PDGF$\mathrm{BB}$, amelogenin, or different combinations of either EMD and PDGF-BB or amelogenin and PDGF-BB were added in $0.2 \%$ DMEM. Control cultures consisted of similarly plated cells in media containing $10 \%$ FBS (positive control) or $0.2 \%$ FBS (negative control) without the addition of proteins. The concentrations of individual factors used were 50, 150, and 250 $\mu \mathrm{g} / \mathrm{ml}$ EMD; 50 and $250 \mu \mathrm{g} / \mathrm{ml}$ recombinant amelogenin protein (rpAmel); and 20, 50, and $100 \mathrm{ng} / \mathrm{ml}$ PDGF-BB. All possible combinations of EMD and PDGF-BB and combinations of amelogenin and PDGF-BB concentrations were also added. At appropriate time points ( $1,3,6$, and 10 days), trypsin was added to each well and allowed to incubate for an additional 5 to 10 minutes. Cell number was determined using a Coulter counter at each of the four time points. Each experiment was performed in triplicate using two different cell lines of PDL fibroblasts.

\section{In Vitro Cell-Layer Wounding}

Using tissue-culture plates (six-well), PDL cells were seeded at a concentration $5 \times 10^{4}$ per well. The seeded cells were allowed to reach $90 \%$ confluence in DMEM with $10 \%$ fetal calf serum without antibiotics and a humidified atmosphere of $5 \% \mathrm{CO}_{2}$ and $95 \%$ air. The cells were then synchronized by replacing their culture medium with DMEM without serum for 24 hours. The experimental wound was created as previously described by Lackler et al. ${ }^{44}$ Briefly, a sterile $3-\mathrm{mm}$ wide soft rubber policeman was used to scrape off a 3-mm wide cell layer down the middle of the well. The scraped cell layer was gently rinsed three times with DMEM without serum to ensure that all cellular and extracellular debris were removed from the wound site. A long linear scratch under the well marked both edges of the wound; these marks served as the starting point for cells repopulating the wound area. Treatment medium was added according to the experimental design. Control cultures consisted of $10 \%$ FBS (positive control) or $0.2 \%$ FBS (negative control) without the addition of proteins. The concentrations of individual factors used were 50 and $250 \mu \mathrm{g} / \mathrm{ml}$ EMD, 50 and $250 \mu \mathrm{g} / \mathrm{ml} \mathrm{rpAmel}$, and 20 and 100 $\mathrm{ng} / \mathrm{ml}$ of PDGF-BB. Different combinations of EMD and PDGF-BB and different combinations of amelogenin and PDGF-BB were added together as noted in the results. Cells were treated for $1,3,6$, and 10 days. The concentrations of EMD and PDGF-BB used were based on preliminary experiments in our laboratory (data not shown) and previously published studies. ${ }^{37,45}$ The concentration of amelogenin was the same as the concentration of EMD, based on the $>90 \%$ amelogenin content of EMD. Effects of different factors in both growth and wound fill were most dramatic at days 6 and 10. Because day- 6 data showed similar trends as day-10 data, only day-10 data are presented for simplification of figures.

At an appropriate time point, cells were fixed with $100 \%$ ethanol and stained with crystal violet. Quantification of wound repopulation was accomplished using a light microscope equipped with a computerassisted digital image analyzer. $\S \S$ Four areas of interest (AOI), each having a total area of $0.75 \mathrm{~mm}^{2}$, were analyzed (Fig. 1). AOI 1 was within the established cell monolayer; AOI 2 was within the established cell monolayer adjacent to the wound edge; AOI 3 was within the wound space adjacent to the wound edge; and AOI 4 was within the wound space at the midline of the $3-\mathrm{mm}$ wound. To eliminate investigator bias, the four specific areas of interest were randomly selected.

\section{Statistical Analysis}

Data analysis was performed using a statistical program. I|| Within each experiment, each test group was run in replicates of three to six depending on the experiment. The mean and variation of the replicates for each test group was determined, and the groups within the experiment were compared using multiple comparison analysis of variance (ANOVA).

\footnotetext{
\# Titertek Multiscan Plus, Titertek, Huntsville, AL.

* * Pierce, Rockford, IL

$\dagger \dagger$ Titertek Multiscan Plus, Titertek.

㭋 Emdogain, Biora, Malmö, Sweden.

$\S \S$ Image Pro Plus, Media Cybernetics, Silver Spring, MD.

I|| Statgraphics Plus 5.0, Manugistics, Rockville, MD.
} 


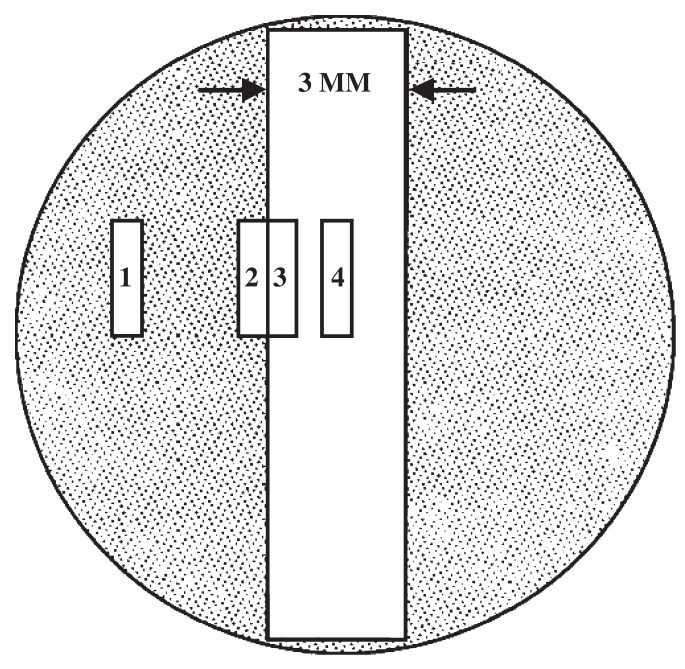

Figure I.

In vitro cell layer wound model. $\mathrm{AOI} I$ is located within the confluent cell layer. AOI 2 is located at the confluent cell layer edge. AOI 3 is located at the wound edge. AOI 4 is located at the center of the wound.

Tukey's honest significant difference (HSD) method was used as a post-hoc test to determine the significance between different concentrations. The $P$ value was set at the 0.05 level of significance.

\section{RESULTS}

\section{Alkaline Phosphatase Assay}

The histochemical staining for alkaline phosphatase activity in two different cell lines showed greater activity for one cell line (ALK PHOS [+]) than for the other cell line (ALK PHOS [-]), which only showed minimal histochemical staining (Fig. 2). Alkaline phosphatase specific activity calculated from optical density values once again shows greater activity for ALK PHOS (+) and very little activity for ALK PHOS (-) (Fig. 2).

\section{Cell Proliferation Assay}

Proliferation assays showed distinct differences between the two cell lines. Proliferation data for ALK PHOS (+) fibroblasts demonstrated no significant effects by EMD or amelogenin, but a statistically significant enhancement of PDL-fibroblast proliferation over negative control media at day 10 was seen with PDGF-BB at concentrations of 50 and $100 \mathrm{ng} / \mathrm{ml}$. In addition to PDGF-BB alone, combinations of PDGF$\mathrm{BB}$ with $\mathrm{EMD}$ or amelogenin produced significant cell growth at days 6 and 10 . On day 10, all combinations of EMD and PDGF-BB, except the combinations of 50 $\mu \mathrm{g} / \mathrm{ml} \mathrm{EMD} \mathrm{+} 20 \mathrm{ng} / \mathrm{ml}$ PDGF-BB and $250 \mu \mathrm{g} / \mathrm{ml}$ $\mathrm{EMD}+20 \mathrm{ng} / \mathrm{ml}$ PDGF-BB, significantly increased cell numbers compared to the negative control. Similarly, the combinations of amelogenin and PDGF-BB increased the cell number. By contrast, the prolifera-

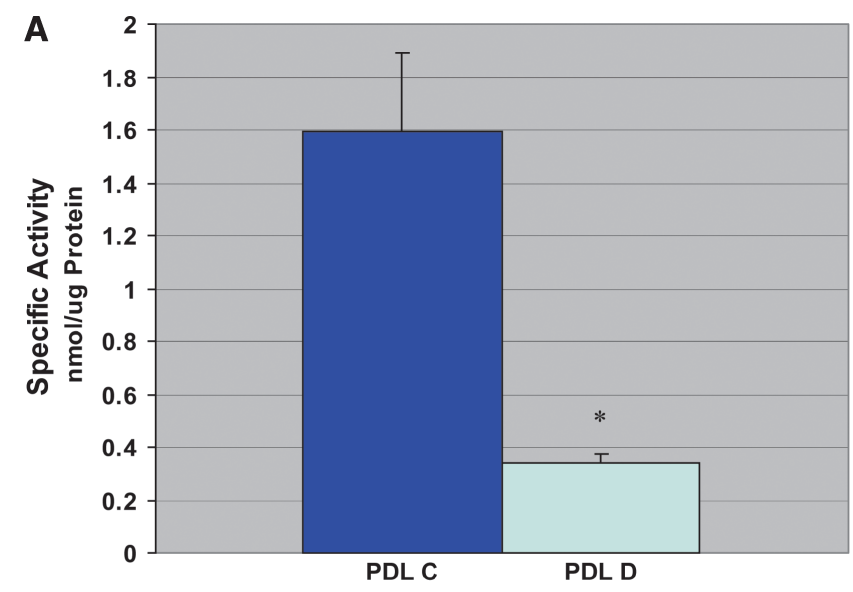

B

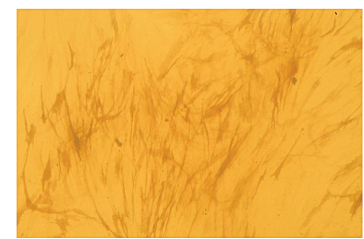

ALK PHOS (+)/PDL C

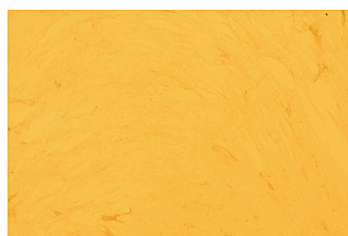

ALK PHOS (-)/PDL D
Figure 2.

Alkaline phosphatase-specific activity (A) and histochemical staining (B). ALK PHOS (+) showed abundant alkaline phosphatase activity by a majority of the cells in the monolayer. By contrast, ALK PHOS (-) showed little or no alkaline phosphatase activity in the monolayer. The results of the enzyme activity assay were consistent with the histochemical results. Note that the alkaline phosphatase-specific activity in the ALK PHOS (+) cells is approximately five-fold greater than the activity in the ALK PHOS (-) cells (A). *Statistically significant at $\mathrm{P}<0.05$ compared to $P D L C$.

tion assays for ALK PHOS (-) fibroblasts demonstrated an increase in cell number over time in the positive control, but no significant increase was noted in cell numbers with the factors by themselves. Only the combinations of EMD and PDGF-BB significantly increased cell numbers at days 6 and 10 (Fig. 3). However, the combinations of amelogenin and PDGF-BB did not show a similar increase in ALK PHOS (-) cell proliferation. Other differences between the two cell lines are that significant cell proliferation by PDGF$\mathrm{BB}$ and the combinations of PDGF-BB with either EMD or amelogenin was greater than the positive control for ALK PHOS $(+)$ cells. However, at no time did EMD and PDGF-BB combinations show greater increases in cell proliferation for the ALK PHOS (-) cell line than the positive control.

\section{In Vitro Cell-Layer Wounding}

Wound assays for the two different cell lines of PDL fibroblasts demonstrated variations in the magnitude, but similar trends were seen in both cell lines in response to EMD, PDGF-BB, and amelogenin. In AOI 3 of the ALK PHOS (+) cell line at day 10, a 


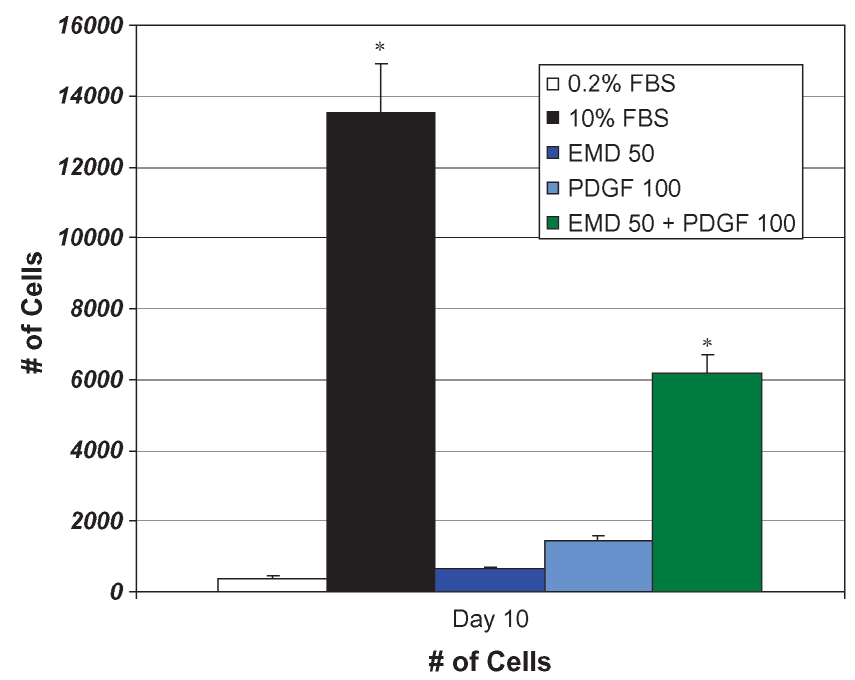

Figure 3.

ALK PHOS (-) cell proliferation response to EMD, PDGF-BB, and combinations of EMD + PDGF-BB. ALK PHOS (-) cells showed statistically greater responses to the concentrations of $50 \mu \mathrm{g} / \mathrm{ml}$ $E M D+100 \mathrm{ng} / \mathrm{ml}$ PDGF-BB than either $50 \mu \mathrm{g} / \mathrm{ml}$ EMD or $100 \mathrm{ng} / \mathrm{ml}$ PDGF-BB alone. *Statistically significant at $\mathrm{P}<0.05$ compared to $0.2 \% \mathrm{FBS}$.

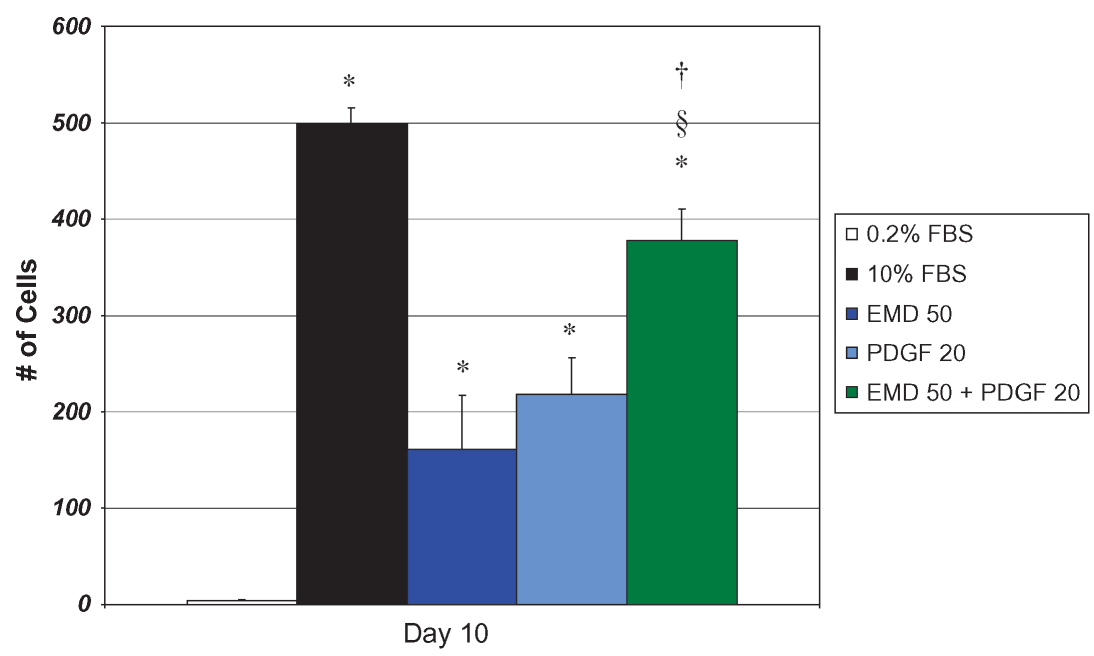

\section{Figure 4.}

ALKPHOS (-) cell wound-fill response to combinations of EMD + PDGF-BB at AOI 3 on day 10. The ALKPHOS (-) cell line showed statistically significant wound-fill responses at $A O I 3$ to all combinations of EMD and PDGF-BB at day 10. Combination responses except EMD $50 \mu \mathrm{g} / \mathrm{ml}+$ PDGF $20 \mathrm{ng} / \mathrm{ml}$ were no greater than the PDGF-BB response alone. The EMD $50 \mu \mathrm{g} / \mathrm{ml}+$ PDGF $20 \mathrm{ng} / \mathrm{ml}$ response showed statistically greater wound fill than the response to PDGF $20 \mathrm{ng} / \mathrm{ml}$. *Statistically significant at $\mathrm{P}<0.05$ compared to $0.2 \%$ FBS. ${ }^{\dagger}$ Statistically significant at $\mathrm{P}<0.006$ compared to EMD $50 \mu \mathrm{g} / \mathrm{ml}$. \$Statistically significant at $\mathrm{P}<0.006$ compared to PDGF-BB $20 \mathrm{ng} / \mathrm{ml}$.

concentration of $250 \mu \mathrm{g} / \mathrm{ml}$ EMD significantly increased cell numbers compared to the negative control, but the response to amelogenin was not statistically significant. Similarly, the ALK PHOS (-) cell line responded to 50 and $250 \mu \mathrm{g} / \mathrm{ml} \mathrm{EMD} \mathrm{with} \mathrm{sig-}$ nificant wound fill, but wound fill with amelogenin did not exhibit a significant wound-fill response. PDGFBB concentrations of 20 and $100 \mathrm{ng} / \mathrm{ml}$ showed significant wound fill compared to the negative control in AOI 3 of ALK PHOS $(+)$ and ALK PHOS $(-)$ cell lines. When the specific factors were combined, both PDL cell lines showed significant wound fill. All combinations of EMD and PDGF-BB in both PDL cell lines were statistically significant. In ALK PHOS (-) cells, 50 $\mu \mathrm{g} / \mathrm{ml}$ EMD combined with PDGF-BB showed a trend for greater wound fill at AOI 3 than $250 \mu \mathrm{g} / \mathrm{ml} \mathrm{EMD}$ combined with PDGF-BB, but it was not statistically significant. The ALK PHOS (-) cell response to 50 $\mu \mathrm{g} / \mathrm{ml}$ EMD + $100 \mathrm{ng} / \mathrm{ml}$ PDGF-BB showed statistically greater wound fill at AOI 3 than either $50 \mu \mathrm{g} / \mathrm{ml}$ EMD or $100 \mathrm{ng} / \mathrm{ml}$ PDGF-BB alone (Fig. 4). Similar to the EMD + PDGF-BB combination response, all combinations of amelogenin and PDGF-BB for both cell lines showed significant wound fill. However, in both cell lines, the responses from combinations of amelogenin and PDGF-BB were similar in magnitude to PDGF-BB alone. This similar level of wound fill achieved by PDGF-BB alone and in combination with amelogenin suggests that the effects of the amelogenin combination may be solely due to the PDGF-BB effect only, whereas EMD in combination with PDGF seems to have an additive effect in wound fill for ALK PHOS (-) cells.

The wound-fill response to EMD was different at the center of the wound (AOI 4) compared to the response at the wound edge (AOI 3). In AOI 4, neither EMD nor amelogenin showed significant wound fill compared to the negative control in either PDL cell line, but only PDGF-BB and combinations of PDGF-BB with either EMD or amelogenin showed significant wound fill in both PDL cell lines. In the ALK PHOS $(+)$ cell line, the wound-fill response to PDGF-BB was significant on days 6 and 10. In the ALK PHOS (-) cell line, PDGF-BB had a significant effect only on day 10. In ALK PHOS (+) cells, 250 $\mu \mathrm{g} / \mathrm{ml}$ EMD + $100 \mathrm{ng} / \mathrm{ml}$ PDGF-BB showed statistically greater wound fill than $250 \mu \mathrm{g} / \mathrm{ml}$ EMD alone or 100 ng/ml PDGF-BB alone (Fig. 5). In ALK PHOS (-) cells, $50 \mu \mathrm{g} / \mathrm{ml}$ EMD +20 $\mathrm{ng} / \mathrm{ml}$ PDGF-BB showed statistically greater wound fill than either $50 \mu \mathrm{g} / \mathrm{ml}$ EMD alone or $20 \mathrm{ng} / \mathrm{ml}$ PDGF-BB alone (Fig. 6). Combinations of amelogenin and PDGF-BB also showed significant wound fill. However, the amount of wound fill with 


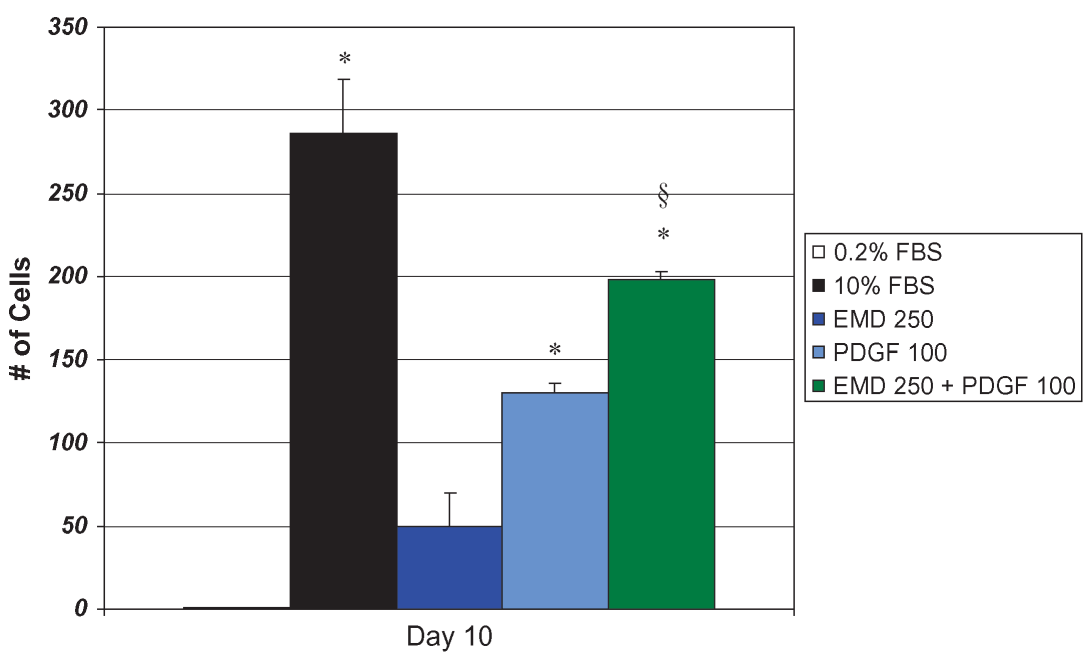

Figure 5.

ALK PHOS (+) cell wound-fill response to combinations of EMD + PDGF-BB at AOI 4 on day 10. The ALK PHOS (+) cell line showed statistically greater wound fill compared to negative control at AOI 4 to all combinations of EMD and PDGF-BB at day 10. Combination responses except EMD $250 \mu \mathrm{g} / \mathrm{ml}+$ PDGF $100 \mathrm{ng} / \mathrm{ml}$ were no greater than the PDGF-BB response alone. The EMD $250 \mu \mathrm{g} / \mathrm{ml}+$ PDGF $100 \mathrm{ng} / \mathrm{ml}$ response showed statistically greater wound fill than the response to PDGF $100 \mathrm{ng} / \mathrm{ml}$. *Statistically

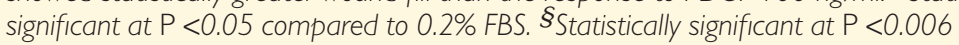
compared to PDGF-BB $100 \mathrm{ng} / \mathrm{ml}$.

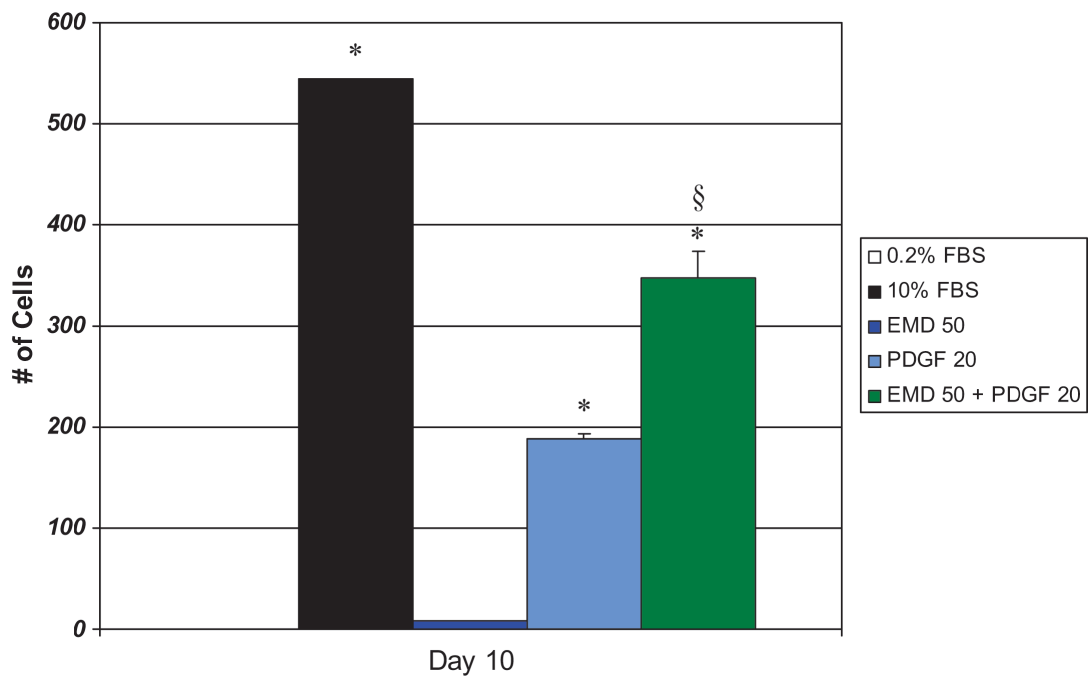

\section{Figure 6.}

ALKPHOS (-) cell wound-fill response to combinations of EMD + PDGF-BB at AOI 4 on day 10. The ALKPHOS (-) cell line showed statistically significant wound fill at AOI 4 to all combinations of EMD and PDGF-BB at day 10. Combination responses except EMD $50 \mu \mathrm{g} / \mathrm{ml}+$ PDGF $20 \mathrm{ng} / \mathrm{ml}$ were no greater than the PDGF-BB response alone. The EMD $50 \mu \mathrm{g} / \mathrm{ml}+$ PDGF $20 \mathrm{ng} / \mathrm{ml}$ response showed statistically greater wound fill than the response to PDGF $20 \mathrm{ng} / \mathrm{ml}$. *Statistically significant at $P<0.05$ compared to $0.2 \%$ FBS. \$Statistically significant at $\mathrm{P}<0.006$ compared to PDGF-BB $100 \mathrm{ng} / \mathrm{ml}$.

amelogenin and PDGF-BB combined treatment was similar to the amount of wound fill achieved by PDGF-BB alone (Fig. 7). This similar level of wound fill achieved by PDGF-BB alone and in combination with amelogenin again suggest that the effects of amelogenin combination may be solely due to the PDGF-BB effect only, whereas $E M D$ in combination with PDGF seems to have an additive effect on wound fill at the center of the defect.

\section{DISCUSSION}

Periodontal wound regeneration requires recruitment of connective tissue cells to the site, proliferation of these cells, and the synthesis of new tissue to replace the destroyed connective tissue component. For these processes to occur, the cells require extracellular matrix for attachment and the local release of cytokines to additionally signal the cells. In recent years, the application of either the extracellular matrix or a myriad of growth factors in periodontal defects to promote regeneration has received prominent attention. However, to our knowledge, no study to date has looked at the combination of extracellular matrix and growth factors in achieving the regeneration of periodontal defects.

EMD has been studied extensively and shown to promote clinical periodontal regeneration. However, its mechanism of action has yet to be determined. It has been speculated that amelogenin, the major component of EMD, is the active component in this process, but this has yet to be proven.

PDL fibroblasts have the capacity to regenerate a periodontal defect with cementum, bone, and periodontal ligament by differentiating into cells of cementogenic, osteogenic, and fibroblastic lineage. ${ }^{46,47}$ Carnes et al. ${ }^{48}$ were able to isolate fibroblasts with osteogenic characteristics compared to cells with fibroblasic characteristics using the expression of alkaline phosphatase activity and osteocalcin release. Fibroblasts that produced high alkaline phosphatase typically formed mineralized matrix. ${ }^{48}$ Thus, different phenotypes of PDL fibroblasts can be isolated and may respond differently to attempts at regeneration through biomimetics and may explain the seemingly contradictory results in published studies regarding the in vitro effects of EMD.

In this study, two different cell types were characterized, and their response to EMD, PDGF-BB, and 


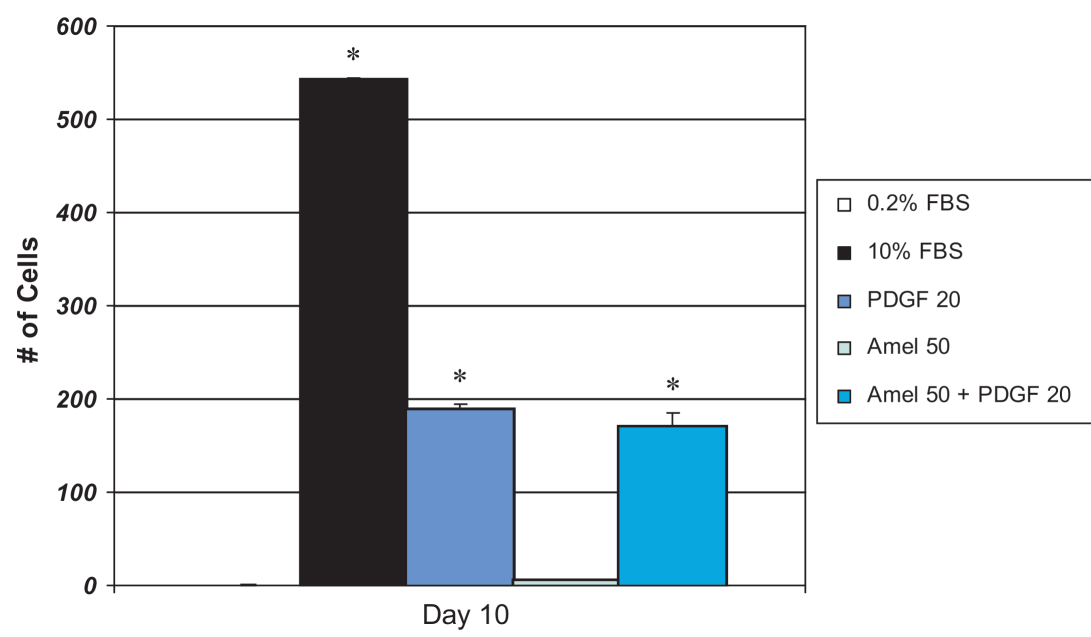

Figure 7.

ALK PHOS (-) cell wound-fill response to combinations of amelogenin + PDGF-BB at AOI 4 on day 10 . The ALK PHOS (-) cell line showed a statistically significant wound fill at AOI 4 to all combinations of amelogenin and PDGF-BB at day 10 , but the combination responses were no greater than the response to PDGF-BB alone. *Statistically significant at $\mathrm{P}<0.05$ compared to $0.2 \%$ FBS. amelogenin were studied. Of the primary cells harvested, ALK PHOS (+) cells showed high alkaline phosphatase activity, which suggests an osteoblastic phenotype, whereas the lack of alkaline phosphatase activity of ALK PHOS (-) cells was more typical of fibroblasts. Accordingly, each primary PDL cell line gave different results for proliferation. The results from the proliferation assay of the ALK PHOS (+) cell line showed that PDGF-BB and the combinations of PDGF-BB with EMD or amelogenin produced significantly greater responses than the negative control. In the ALK PHOS (-) cell line, PDGF-BB did not have a statistically significant effect, and only the combination therapy of EMD and PDGF-BB produced significantly greater proliferative responses. Surprisingly, neither EMD nor amelogenin had statistically significant effects in either cell line. The difference in proliferative results suggests that different cell phenotypes respond differently in the presence of extracellular matrix and cytokines. More specifically, PDGF-BB elicited significant proliferative responses mainly in alkaline phosphatase positive cells. In ALK PHOS (-) PDL fibroblasts, EMD enhanced the PDGF-BB response to produce significantly greater proliferation (Table 1 ).

A possible explanation for this enhanced PDGF-BB response in combination with EMD may be attributed to the binding properties of the fibroblasts to the extracellular matrix. Fibroblast functions such as proliferation and migration are initiated by cell attachment. In typical in vitro experiments, fibroblast viability can be verified by microscopic examination of cell attachment. Characteristic changes in morphology from a round to elongated shape indicate fibroblast attachment and survival. Fibroblasts attach to the extracellular matrix partly through integrin binding, and the resultant change in the cell morphology as it attaches to EMD may expose more PDGF-BB receptors. ${ }^{49}$ Thus, the fibroblast proliferative response may be increased through greater PDGF-BB binding to receptor sites on attached fibroblasts.

PDGF stimulates fibroblasts by binding to $\alpha$ - and $\beta$-receptors found on the cell surface. The presence of different PDGF receptors on PDL fibroblasts has been shown to be influenced by autocrine factor production. One such factor, TGF- $\beta$, has been implicated in changing PDGF-BB affinity to fibroblasts. Oates et al. ${ }^{33}$ have shown a decrease in $\alpha$-receptor subunits but increased $\beta$-receptor subunits by PDL fibroblasts after exposure to TGF- $\beta$. This selective receptor 
expression can upregulate PDGF-BB binding to fibroblasts. In a recent study, ${ }^{20}$ periodontal fibroblasts in the presence of EMD showed an increased autocrine production of TGF- $\beta$. This increase in TGF- $\beta$ may also explain the enhanced PDGF-BB response through increased $\beta$-receptors by EMD stimulated PDL fibroblasts. It is interesting that PDGF-BB had greater proliferative effects on only ALK PHOS (+) cells, whereas PDGF-BB's proliferative effects on ALK PHOS (-) cells required EMD to be significant.

The differences in proliferative response by ALK PHOS (+) and ALK PHOS (-) cells were also seen at the wound edge, but the wound-fill response by the PDL fibroblasts was similar for both PDL cell lines at the center of the wound. The results of the data at the wound margin (AOI 3 ) showed that both cell lines responded with significantly greater wound fill at the wound margin in response to EMD and PDGF-BB individually, but only the ALK PHOS (-) cell line showed an additive response to a combination of EMD and PDGF-BB. However, this trend did not continue at the center of the wound (AOI 4). At the center of the wound, only PDGF-BB and PDGF-BB in combination with EMD or amelogenin produced greater wound fill, whereas EMD and amelogenin by themselves did not increase wound-fill responses. However, the combined EMD and PDGF-BB were additive, whereas the amelogenin and PDGF-BB combination results seem to be the result of the PDGF-BB response alone (Figs. 6 and 7).

Thus, PDGF-BB consistently enhanced wound fill, whereas EMD produced significant wound-fill effects at close proximity of the wound margin but was ineffective further away from the wound margin. However, EMD in combination with PDGF-BB additively increased wound fill at the center of the wound compared to EMD or PDGF-BB alone. We can speculate from the proliferation and the wound-fill data that EMD used alone significantly enhances wound healing only at close proximity to the wound edge but may exert significant effects at areas further away from the wound edge by interacting with PDGF-BB. Also, ALK PHOS $(-)$ cells are more sensitive than ALK PHOS $(+)$ cells to the additive effects of EMD in combination with PDGF-BB in proliferation and wound fill. These findings are in agreement with in vivo study results using a baboon model, in which EMD showed greater regenerative effects in defects $<2 \mathrm{~mm}$ compared to larger defects $\geq 4 \mathrm{~mm} .{ }^{50}$ Clinically, EMD enhances significantly greater defect fill in narrower defects, and the current in vitro findings suggest limitations of EMD use alone in wider periodontal defects. By combining EMD and PDGF-BB in a periodontal defect, a greater defect fill may be expected even in larger defects.

When comparing the effects of amelogenin to the effects of EMD on the PDL fibroblasts, similar concen- trations would have been thought to provide similar results. This is because amelogenin composes $\sim 90 \%$ or more of EMD. However, amelogenin did not have the same additive effect on PDL-fibroblast proliferation in combination with PDGF-BB as EMD had in combination with PDGF-BB. In the wound-fill model, EMD consistently outperformed amelogenin in PDLfibroblast wound fill at the wound edge, and produced greater wound fill as an additive response with PDGF$\mathrm{BB}$. The significant proliferation and wound healing effects of amelogenin in combination with PDGF-BB seem to be mostly the effects of PDGF-BB alone. Thus, amelogenin by itself did not affect the proliferation or the migration of PDL fibroblasts, nor did it have any additive effects in combination with PDGF$\mathrm{BB}$. This suggests that amelogenin by itself may not be the sole active component in EMD as commonly assumed and that other enamel matrix proteins in EMD, or combinations of other enamel matrix proteins working in concert with amelogenin, may be responsible for the efficacy of EMD.

\section{CONCLUSIONS}

The results of these in vitro experiments validate the clinical effects of EMD by suggesting several possible mechanisms. First, EMD by itself has limited effects on PDL fibroblast proliferation. However, EMD can enhance the proliferative effects of PDGF-BB on ALK PHOS (+) fibroblast lineage. Second, EMD enhances wound fill rates in ALK PHOS (+) and ALK PHOS (-) fibroblasts, primarily near the wound edge, and additively with PDGF-BB at the center of the wound. Third, the regenerative effects of EMD cannot be attributed to amelogenin alone.

The results of this study propose several new concepts of EMD and its effects on periodontal regeneration. According to Hoang et al., ${ }^{49}$ amelogenin in EMD promotes cell adhesion activity. Because amelogenin binds to hydoxyapatite, EMD may enhance attachment of fibroblasts to root surfaces. ${ }^{49}$ In addition to enhancing fibroblast attachment in a periodontal defect, EMD may directly enhance proliferation of nonmineralizing PDL fibroblasts into the defect, a crucial aspect for enhanced periodontal ligament regeneration. But even more importantly, EMD may initiate the migration of PDL fibroblasts to the periodontal defect by enhancing the affinity of the cells for PDGF-BB. The additive effects of EMD and PDGF-BB in increasing wound-fill rates in a dose-dependent manner suggest a possible benefit in combining an extracellular matrix such as EMD and a cytokine growth factor such as PDGF-BB in a broad periodontal defect to achieve even greater predictability in the regeneration of a lost periodontium. Further studies combining EMD and PDGF-BB therapy may expand the findings of this current in vitro study to the clinic. Furthermore, and 
surprisingly, the effects of EMD on PDL fibroblasts differ greatly from the effects of its main component, amelogenin. Amelogenin has been studied extensively for its perceived effects on periodontal regeneration as the primary constituent of EMD, whereas other enamel matrix protein components of EMD are frequently overlooked in experimental designs. The results of the current study also suggests that future efforts in quantifying the regenerative potential of EMD should focus more on these other enamel matrix proteins and their combined effects with amelogenin.

\section{ACKNOWLEDGMENT}

The views expressed in this article are those of the authors and are not to be construed as official or as reflecting the views of the United States Air Force or Department of Defense.

\section{REFERENCES}

1. Slavkin H. Towards a cellular and molecular understanding of periodontics. Cementogenisis revisited. $J$ Periodontol 1976;47:249-255.

2. Slavkin H, Bessem C, Fincham A, et al. Human and mouse cementum proteins immunologically related to enamel proteins. Biochim Biophys Acta 1989;991: 12-18.

3. Hammarstrom L. Enamel matrix, cementum development and regeneration. J Clin Periodontol 1997;24: 658-668.

4. Sculean A, Donos N, Windisch P, et al. Healing of human intrabony defects following treatment with enamel matrix proteins or guided tissue regeneration. J Periodontal Res 1999;34:310-322.

5. Yukna R, Mellonig J. Histologic evaluation of periodontal healing in humans following regenerative therapy with enamel matrix derivative. A 10-case series. J Periodontol 2000;71:752-759.

6. Heijl L. Periodontal regeneration with enamel matrix derivative in one human experimental defect. A case report. J Clin Periodontol 1997;24:693-696.

7. Heijl L, Heden G, Svardstrom G, Ostgren A. Enamel matrix derivative (EMDOGAIN) in the treatment of intrabony periodontal defects. J Clin Periodontol 1997; 24:705-714.

8. Froum S, Weinberg M, Rosenberg E, Tarnow D. A comparative study utilizing open flap debridement with and without enamel matrix derivative in the treatment of periodontal intrabony defects: A 12-month reentry study. J Periodontol 2001;72:25-34.

9. Yilmaz S, Kuru B, Altuna-Kirac E. Enamel matrix proteins in the treatment of periodontal sites with horizontal type of bone loss. J Clin Periodontol 2003;30: 197-206.

10. Pontoriero R, Wennstrom J, Lindhe J. The use of barrier membranes and enamel matrix proteins in the treatment of angular bone defects. A prospective controlled clinical study. J Clin Periodontol 1999;26: 833-840.

11. Sculean A, Donos N, Miliauskaite A, Arweiler N, Brecx $M$. Treatment of intrabony defects with enamel matrix proteins or bioabsorbable membranes. A 4-year follow-up split-mouth study. J Periodontol 2001;72: 1695-1701.
12. McGuire M, Cochran D. Evaluation of human reces sion defects treated with coronally advanced flaps and either enamel matrix derivative or connective tissue. Part 2: Histological evaluation. J Periodontol 2003;74: 1126-1135.

13. McGuire M, Nunn M. Evaluation of human recession defects treated with coronally advanced flaps and either enamel matrix derivative or connective tissue. Part 1: Comparison of clinical parameters. J Periodontol 2003;74:1110-1125.

14. Sculean A, Chiantella GC, Miliauskaite A, Brecx M, Arweiler NB. Four-year results following treatment of intrabony periodontal defects with an enamel matrix protein derivative: A report of 46 cases. Int $J$ Periodontics Restorative Dent 2003;23:345-351.

15. Giannobile WV, Somerman MJ. Growth and amelogenin-like factors in periodontal wound healing. A systematic review. Ann Periodontol 2003;8: 193-204.

16. Gestrelius S, Anderssen C, Lidstrom D, Hammarstrom $\mathrm{L}$, Somerman M. In vitro studies on periodontal ligament cells and enamel matrix derivative. $J$ Clin Periodontol 1997;24:685-692.

17. Kawase T, Okuda K, Yoshie H, Burns D. Cytostatic action of enamel matrix derivative on human oral squamous cell carcinoma-derived SCC25 epithelial cells. $J$ Periodontal Res 2000;35:291-300.

18. Boyan B, Weesner T, Lohmann H, et al. Porcine fetal enamel matrix derivative enhances bone formation induced by demineralized freeze dried bone allograft in vivo. J Periodontol 2000;71:1278-1286.

19. Schwartz Z, Carnes D, Pulliam R, et al. Porcine fetal enamel matrix derivative stimulates proliferation but not differentiation of pre-osteoblastic 2T9 cells, inhibits proliferation and stimulates differentiation of osteoblast-like MG63 cells, and increases proliferation and differentiation of normal human osteoblast NHOst cells. J Periodontol 2000;71:1287-1296.

20. Lyngstadaas S, Lundberg E, Ekdahl H, Andersson C, Gestrelius S. Autocrine growth factors in human periodontal ligament cells cultured on enamel matrix derivative. J Clin Periodontol 2001;28:181-188.

21. van der Pauw M, van den Boss T, Everts V, Beertsen W. Enamel matrix-derived protein stimulates attachment of periodontal ligament fibroblasts and enhances alkaline phosphatase activity and transforming growth factor beta1 release of periodontal ligament and gingival fibroblasts. J Periodontol 2000;71:31-43.

22. Fong CD, Hammarstrom L. Expression of amelin and amelogenin in epithelial root sheath remnants of fully formed rat molars. Oral Surg Oral Med Oral Pathol Oral Radiol Endod 2000;90:218-223.

23. Hu J, Sun X, Zhang C, Simmer JP. A comparison of enamelin and amelogenin expression in developing mouse molars. Eur J Oral Sci 2001;102:129-132.

24. Fincham A, Simmer J. Amelogenin proteins of developing dental enamel. Ciba Found Symp 1997;205: 118-130.

25. Simmer J, Lau E, Hu C, et al. Isolation and characterization of a mouse amelogenin expressed in Escherichia coli. Calcif Tissue Int 1994;54:312-319.

26. Boabaid F, Gibson CW, Kuehl MA, et al. Leucine-rich amelogenin peptide: A candidate signaling molecule during cementogenesis. J Periodontol 2004;75:11261136.

27. Lynch S. The role of growth factors in periodontal repair and regeneration. In: Polson AM, ed. Periodontal 
Regeneration: Current Status and Directions. Chicago: Quintessence; 1993:179-198.

28. Boyan L, Bhargava G, Nishimura F, Orman R, Price R, Terranova V. Mitogenic and chemotactic responses of human periodontal ligament cells to the different isoforms of platelet-derived growth factor. J Dent Res 1994;73:1593-1600.

29. Heldin C, Wasteson A, Westermark B. Growth of normal human glial cells in a defined medium containing platelet-derived growth factor. Proc Natl Acad Sci USA 1980;77:6611-6615.

30. Heldin C, Westermark B. Platelet-derived growth factor: Mechanism of action and possible in vivo function. Cell Regul 1990;1:555-566.

31. Matsuda N, Lin W, Kumar N, Cho M, Genco R. Mitogenic, chemotactic, and synthetic responses of rat periodontal ligament fibroblastic cells to polypeptide growth factors in vitro. J Periodontol 1992;63: 515-525.

32. McAllister B, Leeb-Lundberg F, Mellonig J, Olson M. The functional interaction of EGF and PDGF with bradykinin in the proliferation of human gingival fibroblasts. J Periodontol 1995;66:429-437.

33. Oates T, Kose K, Xie J, Graves D, Collins J, Cochran D. Receptor binding of PDGF-AA and PDGF-BB, and the modulation of PDGF receptors by TGF-beta, in human periodontal ligament cells. J Cell Physiol 1995; 162:359-366.

34. Dennison D, Vallone D, Pinero G, Rittman B, Caffesse R. Differential effect of TGF-beta 1 and PDGF on proliferation of periodontal ligament cells and gingival fibroblasts. J Periodontol 1994;65:641-648.

35. Piche J, Carnes D, Graves D. Initial characterization of cells derived from human periodontia. J Dent Res 1989;68:761-767.

36. Oates T, Rouse C, Cochran D. Mitogenic effects of growth factors on human periodontal ligament cells in vitro. J Periodontol 1993;64:142-148.

37. Mumford J, Carnes D, Cochran D, Oates T. The effects of platelet-derived growth factor-BB on periodontal cells in an in vitro wound model. J Periodontol 2001; 72:331-340.

38. Lynch S, Williams R, Polson A, et al. A combination of platelet-derived and insulin-like growth factors enhances periodontal regeneration. J Clin Periodontol 1989;16:545-548.

39. Lynch S, de Castilla G, Williams R, et al. The effects of short-term application of a combination of plateletderived and insulin-like growth factors on periodontal wound healing. J Periodontol 1991;62:458-467.
40. Rutherford R, Niekrash C, Kennedy J, Charette M. Platelet-derived and insulin-like growth factors stimulate regeneration of periodontal attachment in monkeys. J Periodontal Res 1992;27:285-290.

41. Papadopoulos C, Dereka X, Vavouraki E, Vrotsos I. In vitro evaluation of the mitogenic effect of plateletderived growth factor-BB on human periodontal ligament cells cultured with various bone allografts. $J$ Periodontol 2003;74:451-457.

42. Nevins M, Camelo M, Nevins M, Schenk R, Lynch S. Periodontal regeneration in humans using recombinant human platelet-derived growth factor-BB (rhPDGF-BB) and allogenic bone. J Periodontol 2003; 74:1282-1292.

43. Camelo M, Nevins M, Schenk R, Lynch S, Nevins M. Periodontal regeneration in human Class II furcations using purified recombinant human platelet-derived growth factor-BB (rhPDGF-BB) with bone allograft. Int J Periodontics Restorative Dent 2003;23:213-225.

44. Lackler KP, Cochran DL, Hoang AM, Takacs V, Oates TW. Development of an in vitro wound healing model for periodontal cells. J Periodontol 2000;71:226-237.

45. Hoang AM, Oates TW, Cochran DL. In vitro wound healing responses to enamel matrix derivative. J Periodontol 2000;71:1270-1277.

46. Melcher A. On the repair potential of periodontal tissues. J Periodontol 1976;47:256-260.

47. Meyer J. The regenerative potential of the periodontal ligament. J Prosthet Dent 1986;55:260-265.

48. Carnes DL Jr., De La Fontaine J, Cochran DL, et al. Evaluation of 2 novel approaches for assessing the ability of demineralized freeze-dried bone allograft to induce new bone formation. J Periodontol 1999;70: 353-363.

49. Hoang AM, Klebe RJ, Steffensen B, Ryu OH, Simmer JP, Cochran DL. Amelogenin is a cell adhesion protein. J Dent Res 2002;81:497-500.

50. Cochran DL, King GN, Schoolfield J, Velasquez-Plata D, Mellonig JT, Jones A. The effect of enamel matrix proteins on periodontal regeneration as determined by histological analyses. J Periodontol 2003;74:10431055.

Correspondence: Dr. Chol H. Chong, Department of Periodontics, Wilford Hall Medical Center, 1615 Truemper St., Lackland Air Force Base, TX 78236. E-mail: chol.chong@ lackland.af.mil.

Accepted for publication February 14, 2006. 